Weber Martins Batista, juiz de direito da 13 .

Vara Criminal do Rio de Janeiro, professor de

direito processual penal da Universidade do

Estado do Rio de Janeiro.

\title{
Suspensão condicional do procedimento
}

\section{Os males da prisão}

Os malefícios da prisão têm sido ressaltados pela doutrina com tal constância e uniformidade, que se pode dizer, hoje em dia, que é praticamente unânime a conclusão de que a cadeia fracassou como meio de reforma do delinqüente. O que se apregoa, ao contrário, é sua nefasta influência na vida do preso, como verdadeira escola de criminosos.

O século passado presenciou o triunfo da pena privativa de liberdade. Sob a influência dos filósofos do século XVIII, os países civilizados renunciaram à crueldade dos castigos corporais e de todos os atrozes suplícios que outrora eram infligidos aos criminosos como expiação de sua culpa. Com o tempo, diz Charles Germain, não apenas se atenuou o caráter aflitivo da prisão, como se chegou a considerá-la, não tanto sob o aspecto negativo da segregação, mas antes sob o aspecto positivo da possibilidade de utilizar tal período com fins de tratamento. E tornou-se corrente ouvir dizer que a execução da pena de prisão tem como fim essencial a reabilitação do prisioneiro, sua emenda e recuperação social. ${ }^{1}$

A esperança - honesta ou simulada - de alcançar a 'ressocialização', a 'recuperação', a 'readaptação', a 'reinserção', a 'reeducação social', enfim, novos estágios d'alma, sob as mais variadas designações otimistas, penetrou fortemente em sistemas positivos com proclamações retóricas, como aconteceu nas constituições da Itália, de 1947, na da Espanha, de 1978, em códigos como o suíco, o rusSo, o brasileiro, de 1969, em leis penitenciárias, como a da Espanha, de 1979.2
Mas a verdade é que essas proclamações sonoras não raro se exaurem na literalidade dos textos que as encerram. Dificilmente alguém seria capaz de repetir o que disse, recentemente, ilustre professor: "Na execução da pena privativa de liberdade deve-se realcar sua função educativa e ressocializadora," 3 pois o que já se dizia, há muito tempo atrás, é que "los cárceles son, y es doloroso decirlo, verdaderos focos dónde se gesta el delito, se forman los delincuentes. Lejos de disminuir la criminalidad, ella aumenta progresivamente, transformando el primario ocasional en reincidente. "4

Em relatório apresentado ao Colóquio de Belágio, em 1975, J. E. Williams, falando em nome da Sociedade Internacional de Criminologia, disse que em lugar de exigir a reforma das prisões, a questão é saber se a prisão pode reformar 0 infrator e se efetivamente o faz. Deve ser feito todo o possível para evitar que os presos sejam realmente submetidos a um dano e piorem pela experiência de estarem encarcerados. 5

Israel Drapkin, em palestra proferida no Instituto Oscar Freire, em São Paulo, depois de proclamar-se um homem 'com os pés na terra', afirmou que muito se fala em tratamento do delinqüente para sua recuperação, que enchem a boca para dissertar sobre a terapêutica, a laborterapia, a psicoterapia de grupo, quando não se ufanam na biotipologia criminal. Mas, indaga ele, quantos casos de reabilitação de criminosos conhecemos diante da população carcerária do mundo? São tão raros, finali$\mathrm{za}$, que se pode dizer que tudo isso é falso. ${ }^{6}$

Afirmação semelhante faz José Maria Rico, 
depois de citar as cifras de reincidência nos diversos países do mundo civilizado: a verdadeira criminalidade não tem sido influenciada pelos meios utilizados até hoje. 7 Por esses motivos, a quase totalidade dos estudiosos afirma que a prisão falhou em seus objetivos.

\section{A prisão como fator de criminalidade}

Ao descrédito no poder de emenda da prisão se soma, hoje em dia, a opinião quase unânime dos especialistas sobre os malefícios que causa aos detidos. Em contato com outros presos, sofrem eles o chamado processo de prisionalização - ou seja, de adoção de usos, costumes, tradições e cultura geral da penitenciária. O cárcere, com sua disciplina necessária, porém amiúde mal aplicada, cria uma delinqüência específica, capaz de firmar ainda mais o detido em suas tendências criminosas. ${ }^{8}$

Entre nós, há mais de cinqüenta anos o ilustre mestre Roberto Lyra vem proclamando que, "seja qual for o fim atribuído à pena, a prisão é contraproducente. Nem intimida, nem regenera. Embrutece e perverte. Insensibiliza ou revolta. Descaracteriza, priva de funções, inverte a natureza, gera cínicos ou hipócritas. A prisão, fábrica e escola de reincidência, habitualidade, profissionalidade, produz e reproduz criminosos." "g

O aprendizado do crime, a formação de associações de malfeitores são, essencialmente, a triste conseqüência das prisões comuns. Aí estão as tristemente famosas 'falange vermelhas', como frutos da vida em comum nos estabelecimentos penais ao lado de criminosos perigosos e de bom nível de inteligência. ${ }^{10}$

Essa falha da prisão, é doloroso verificar, não resulta do fato de serem os cárceres de ontem verdadeiras 'casas dos mortos'. Entre nós, acrescentese, eles não mudaram muito desde então. Recentemente, uma comissão parlamentar de que faziam parte advogados e professores de direito visitou os estabelecimentos penais do país. O que observou segundo relatório do então deputado Ibrahim-AbiAckel - era o esperado: "Os estabelecimentos prisionais onde se aplica o tratamento penal e as casas de recolhimento de presos, quer se chamem casas de detenção, presídios, cadeias ou institutos penais, não passam de depósitos humanos, onde a degradação é a única resultante." "11

A verdade é que mesmo as moderníssimas prisões, construídas na Europa - como na Suécia, na Suiça - e nos EUA, apesar da preocupação de pôr em prática as idéias de reforma apontadas pela dou- trina, fracassaram completamente. Qualquer que seja o estabelecimento prisional, os índices de reincidência continuam muito altos. De modo que se pode dizer que os réus apenados com outras penas que não sejam a de prisão reincidem em muito menor número do que os que vão, efetivamente, para a cadeia.

\section{As penas alternativas}

Em face disso, não deve causar espanto que penalistas e criminólogos de todo o mundo busquem outras respostas para o desafio do sistema correcional vigente, propondo até mesmo sua abolição. $\dot{E}$ que, embora a maioria seja contrária ao uso da pena de açoites - pena bárbara, medieval - , já existem os que defendem sua volta como substitutiva da prisão, alegando que, apesar de tudo, é ela menos nociva do que esta, o que é verdade. ${ }^{12}$

Alarmado com o grave problema da reincidência, Pisapia questiona: "No ci si può, infatti non domandare se la constatata inefficienza rieducatrice della pena, la cui applicazione non sono valse ad impedire la ricaduta nel delitto, dia da addebitare al colpevole o non piuttosto alle modalità di esecuzione della sanzione applicata." 13

Bettiol reconhece que "amesso che si voglia insistere sullo scopo rieducativo della pena, resta il problema dei risultati. L'esperienza storica ci dice che si é voluta dare una finalità sono stati assai o limitati. Nos è con il diritto e con criterio pedagogico in intimo legame con un istituto giuridico coattivo quale la pena che si transforma l'animo dell'uomo". 14

Mais realista, Vassali comenta que a idéia da pena como fator reeducativo deve levar o juiz e, principalmente, o legislador à busca de outras sanções, que possam, melhor do que a pena de prisão, realizar a finalidade inscrita na Constituição de seu país, sugerindo "un più rigoroso sistema di pene pecuniarie, la sotto posicione a un regime di libertà controllata per un tempo determinato e sopratuto il lavoro obbligatorio o altre prestazioni di pubblica utilità in regime di libertà e di semilibertà personale." 15

Aliás, uma das penas substitutivas mais adotadas no mundo inteiro é a de multa. Eu próprio, quando moço, entusiasmei-me por ela e cheguei a escrever um estudo apontando os ilícitos onde a lei deveria permitir que os juízes impusessem aos condenados, em certas circunstâncias, tão-só a pena de multa. Hoje, no entanto, depois de longa experiência como promotor e juiz, perdi grande parte do entusiasmo inicial.

A pena de multa não atinge duas classes, a segunda delas, numerosíssima: os muito ricos e os muito pobres. Aqueles, porque não a sentem; es- 
tes, porque não pagam. Além disso, ela é normalmente onerosa para os homens da classe média alta, é muito onerosa para os da classe média baixa e é insuportavelmente onerosa para os pobres não miseráveis - classe que tem crescido muito ultimamente; e, o que é pior, enseja alguns arranjos capazes de burlarem a lei.

Na Alemanha de hoje está surgindo um problema sério. Os empregados de algumas empresas gozam de um seguro para cobrir o pagamento de multas penais. Assim, se alguém quiser agredir o vizinho, pode fazê-lo impunemente; pois, se for condenado, a empresa paga por ele a pena de multa, prevista para o fato. O único problema é que o vizinho, que também tem seguro, pode querer fazer o mesmo com ele. Esse problema, depois de deixar a jurisprudência perplexa, está ocasionando uma reação contrária, não apenas à adoção do seguro que é imoral e ilegal - como a própria pena de multa, que permite soluções como esta.

Aquelas idéias e este problema não podiam deixar de refletir-se nas legislações dos povos cultos, que têm procurado minorar o problema com a adocão de novas modalidades de penas restritivas de direitos. Entre nós,o recente Anteprojeto de Código penal consagra dois substitutivos muito bons: a prestação de serviços gratuitos à comunidade e o aprendizado compulsório.

A primeira consiste na atribuição ao condenado de trabalho gratuito junto a entidades assistenciais, hospitais, escolas, orfanatos e outros estabelecimentos congêneres, ou em programas comunitários cumpridos em fins de semana ou nos dias comuns, fora do horário normal de trabalho do apenado. A segunda, na freqüência a curso ou ciclo de palestras, no qual o condenado por crime culposo venha a adquirir conhecimentos necessários a evitar a ocorrência de nova infração e a estimular o dever social de cuidado. ${ }^{16}$

Estas idéias novas, como é natural, costumam ser recebidas com certa reserva. No Seminário sobre a Reforma dos Códigos Penal e de Processo Penal, realizado pela Escola Superior de Magistratura Nacional, ${ }^{17}$ a quase totalidade dos juízes presentes pareceu repudiar as modificações propostas, por achá-las retóricas, utópicas, pouco práticas, de difícil aplicação no país. Acontece que essas penas têm dado excelentes resultados em outros países, onde a busca de alternativas para a prisão vem provocando uma diminuição sensível da população carcerária.

Segundo dados fornecidos em trabalho recente de Heleno Fragoso, eis alguns dos resultados conseguidos: na Romênia, com a modificação legislativa de 1977, apena de trabalho sem privação de li- berdade pode substituir qualquer pena privativa de liberdade de até cinco anos. Assim, enquanto no ano de $1976,66 \%$ das sentenças condenatórias impunham pena de prisão, essa porcentagem caiu para 29,4\% em 1979: Na Austria, a queda foi de $40 \%$ para 23\%, de 1971 para 1977. No Japão, país onde se registram hoje os menores índices de criminalidade no mundo, no ano de 1977 , para 5,9\% de sentencas condenatórias impondo pena de prisão houve $94,1 \%$ impondo outros tipos de punição. ${ }^{18}$

\section{Sursis e probation}

Apesar desses resultados, continua existindo uma certa resistência à adoção dessas penas, mas o mesmo não acontece com a suspensão condicional da pena ou com a probation, que obtiveram grande simpatia da doutrina e do direito positivo dos povos cultos em geral. Com esses institutos, evitase que o condenado (ou o julgado culpado) sofra os malefícios da cadeia, pois em ambas as hipóteses é ele colocado ou mantido em liberdade.

A legislacão brasileira acolheu o sursis, instituto preferido pelos países latinos. A princípio, o benefício só era concedido aos réus condenados a uma pena de detenção ou de prisão simples, mas as virtudes do instituto são tão evidentes que a suspensão foi estendida à pena de reclusão. Hoje, quando o réu é primário ${ }^{19}$ e não perigoso, e é condenado a pena não superior a dois anos, seja ela qual for, o juiz pode suspender sua execução e submeter o beneficiado a um período de prova, durante o qual estará sujeito a certas obrigações. Se vencer o período sem descumpri-las, a pena é julgada extinta.

A principal diferença entre um instituto e outro reside no fato de que, no sursis, o réu é condenado e, só depois disso, a execução da pena é suspensa. Na probation o réu não chega a ser condenado: como entre a instrução e a sentença condenatória há uma fase em que o réu é declarado culpado, se o juiz verifica, nessa ocasião, que estão presentes os pressupostos que permitem a concessão da medida, o processo é suspenso sem condenação e o beneficiado é posto em regime de prova. Passado esse período sem problema, julga-se extinto o processo e o réu não perde a condição de primário.

$\mathrm{Na}$ suspensão condicional da pena, na forma adotada entre nós, como existe uma sentença condenatória, o bom comportamento do réu implica tãosó na extinção da pena, não no desaparecimento da condenação - o que constitui um defeito do instituto.

Qualquer que seja a opinião dos estudiosos sobre a pena de prisão, os dois institutos só oferecem vantagens. Se alguém ainda acredita que a prisăo pode concorrer para melhorar o detido, para rege- 
nerá-lo, sabe que essa é uma tarefa que demanda tempo, sendo incompatível com as penas de curta duração. E aqueles que 'têm os pés na terra', e sabem que a prisão só serve para piorar os presos, não duvidam de que evitar pôr na cadeia os criminosos não perigosos significa não correr o risco de piorálos, de adestrá-los no crime - que é o que, na realidade, acontece.

Os bons resultados alcançados pelos dois institutos são tão evidentes que vêm sendo ampliados no mundo inteiro, visando não apenas aumentar as vantagens do benefício, mas também atingir um número cada vez maior de beneficiados. Alguns códigos europeus (como o suíço, o francês) e sulamericanos (como o argentino) já consagram o que se denomina 'condenação condicional': decorrido o período de prova sem descumprimento das obrigações, a condenação é julgada extinta, readquirindo o condenado a condição de primário.

Há, além disso, como ocorreu entre nós com a recente lei 6.416 , de 1977 , uma tendência, quase que se pode dizer universal, para estender o beneficio aos condenados a penas maiores que as acolhidas até então, e de alcançar até mesmo os reincidentes, desde que se possa supor que não são perigosos. Nos EUA a jurisprudência vem ampliando o alcance da probation, de tal modo que há decisões concedendo-a naqueles casos em que a prova já produzida torna evidente a existência de seus pressupostos, mesmo antes da fase de declaração de culpa do réu. ${ }^{20}$

Raras são as crítıcas que se fazem à suspensão condicional da pena, e, assim mesmo, o que se nota é que se dirigem, não propriamente contra o instituto, em si, mas contra o modo como está regulado nos códigos ou as distorções práticas em sua aplicação, problema que, como é evidente, transcende os domínios do direito penal, "para se radicar nos territórios ainda indivisos e mais ou menos abandonados do direito de execução penal" 21

\section{A suspensão condicional do procedimento}

Se as vantagens do sursis são tão evidentes, por que não antecipar sua concessão? ${ }^{22}$ Se ao receberem os autos do inquéritos policial, juiz e promotor verificarem que o autor do ilícito e o fato por ele praticado estão naquelas condições mencionadas - o ilícito é de pequena gravidade, seu autor é primário, tem bons antecedentes, não é perigoso, praticou fato episódico, de ta! modo que ao fim do processo será beneficiado com a suspensão condicional da pena - , por que não antecipar a medida, concedendo-a antes de iniciado o processo em juízo?
Assim, ao invés de ser oferecida a denúncia contra ele, ou de ser esta recebida, o juiz suspende o procedimento e submete o autor do fato a um período de prova, durante o qual este deverá manter boa conduta e satisfazer as obrigações que lhe forem impostas. Entre estas, deve figurar a prestação de serviços à comunidade e, se for o caso, a assistência à vítima do ilicito, duas medidas de grande valor, não apenas em favor da coletividade, como da recuperação moral do autor do delito.

Ao receber o inquérito, o juiz examinará se estão presentes os pressupostos que permitem a concessão da medida, e que dizem respeito ao fato e à pessoa do autor. Só os ilícitos menos graves, praticados por indiciados primários, não perigosos, devem ensejar a suspensão. Se a hipótese comporta a suspensão, verificará, a seguir, se há suficiente prova do fato e da autoria.

Na maioria dos casos, bastam para isso os elementos colhidos no inquérito policial, mas o juiz poderá ouvir o indiciado e proceder a outras indagações - se as julgar necessárias.

No direito italiano, a condenação por decreto deve ser precedida, necessariamente segundo alguns autores, do interrogatório do acusado. Entre nós, como o instituto proposto não implica em condenação do autor do fato, não parece que o interrogatório do indiciado seja imprescindível, mesmo porque o beneficiado terá oportunidade de manisfestar-se sobre a medida, logo a seguir, aceitandoa ou repudiando-a

Concedida a suspensão, o favorecido será intimado para dizer se com ela concorda; se aceitá-la, será posto em regime de prova; se recusá-la, o inquérito voltará ao ministério público para denúncia ou, se esta já foi oferecida, o juiz a receberá e dará início ao processo. Caso o promotor não concorde com a concessão da medida - havia oferecido denúncia, não recebida pelo juiz, que, ao invés disso, concedeu ao denunciado a suspensão condicional do procedimento - , poderá recorrer, em sentido estrito, ao tribunal. Se este modificar a decisão, ou o fizer o próprio órgão de primeiro grau, o processo prosseguirá normalmente.

Uma única desvantagem oferece o instituto: se durante o período de prova o beneficiado deixar de cumprir qualquer obrigação imposta e o benefício ficar sem efeito, deverá ser iniciado o processo contra ele. Ora, como isso ocorrerá um, dois ou três anos depois, é possível que o tempo decorrido traga algum prejuízo para a prova. O defeito, plenamente compensado pelas inúmeras vantagens do instituto, não é maior do que o que já existe hoje, em face do acúmulo de serviço nas varas criminais e nas delegacias de polícia. Mesmo agora, as testemunhas 
costumam ser ouvidas no processo um, dois, três ou mais anos depois do fato.

\section{A legalidade da medida}

Poderá o legislador ordinário consagrar a suspensão do procedimento? Ou seja, poderá o juiz, com base em prova colhida sem a garantia do contraditório e sem ter condenado o indiciado, presumilo culpado e, em conseqüência, conceder-lhe um benefício de que resulta a imposição de medidas restritivas de direito?

Quando o tema foi proposto pela primeira vez, no Seminário da Escola Superior da Magistratura Nacional, em setembro de 1981, ilustre magistrado da Bahia objetou que a adoção do instituto violaria direitos individuais garantidos aos indivíduos na Constituição, pois implicaria em infligir ao indiciado verdadeiras penas sem processo.

Mesmo sem considerar o fato de que aqui não se pode falar, legitimamente, em penas, a crítica não procede. Como não se ignora, as legislações de países avançados consagram hipóteses de condenação sem processo, como é o caso da Itália. Lá, com o processo monitório, conhecido como 'condenação por decreto', o apontado autor de um ilícito pode ser condenado sem defender-se. Basta para isso que se conforme com a decisão imposta pelo juiz com base em elementos colhidos sem a garantia do contraditório.

Nem por isso se diz que foi violado qualquer direito do indiciado, como o da ampla defesa ou o do devido processo legal. Nos casos de pequena importância é possível evitar o debate, presumindo-se o consentimento do acusado. Se ele não se insurge contra a decisão condenatória do juiz, é porque exerceu uma faculdade dispositiva sobre a forma do processo, não no sentido de poder modificá-la, mas no de aceitar a forma mais simples ao invés de exigir a comum. ${ }^{23}$ E o instituto da condenação por decreto alcançou resultados tão expressivos, que foi ganhando adeptos mais numerosos e, com o tempo, foi estendido às hipóteses de delitos. ${ }^{24}$

\section{Vantagens do instituto}

O instituto cuja criação se propõe oferece vantagens consideráveis, pois com ele se antecipa, praticamente, o resultado do processo, com tudo de bom que isso acarreta; logo em seguida à prática do fato - e não um, dois, três ou mais anos depois, como acontece agora - a autor toma conhecimento da reprovação da justiça e, ao mesmo tempo, da oportunidade que lhe é dada de redimir-se do que fez.
A ameaça de processo e condenação, que continua pairando sobre sua cabeça durante o período de prova, tem efeito intimidativo talvez ainda mais eficiente do que a própria pena que Ihe seria imposta. E com uma vantagem: ao invés de aviltálo, como ocorreria se Ihe fosse infligida pena de prisão e a tivesse de cumprir, a suspensão do procedimento concorre para recuperar, para dignificar o autor do ilícito. Sem ir para a cadeia, sem sequer sofrer a pena da condenação, vence ele o período de prova de forma positiva, com dignidade, prestando serviços à comunidade.

Essa medida, bem como a assistência à vítima e outras obrigações que lhe forem impostas, são restrições de direito que sentirá de imediato. Aquelas duas primeiras, notadamente, são de grande valor e as críticas que têm sido dirigidas a elas, pode-se dizer, se voltam contra problemas secundários, dizem respeito à fiscalização de seu cumprimento. Especialmente quanto a esse ponto, parece que os criticos não têm razão.

As outras medidas adotadas no Código como obrigações impostas àqueles a quem é concedida a suspensão condicional da pena, como a proibição de freqüentar certos lugares, de usar bebidas alcoólicas e outras que tais é que não são fiscalizadas. Como não existe um corpo de funcionários especializados para essa fiscalização, é ela entregue, praticamente, à polícia, que não tem preparo nem tempo para realizá-la.

A prestação de serviços à comunidade e a assistência à vítima, no entanto, são realizadas em favor de pessoas físicas ou de entidades como hospitais, escolas, orfanatos etc. , e seu cumprimento interessa diretamente àquelas pessoas ou entidades; sua fiscalização, parece, será mais efetiva do que se estivesse entregue a pessoas nomeadas especialmente para isso.

\section{Vantagens processuais}

As vantagens processuais do instituto não são menores. Uma das maiores preocupações dos processualistas modernos é a de simplificar, a de agilizar o processo, problema difícil, dados os interesses contrários em jogo. De um lado, o ideal seria demorar tanto o processo que se esgotassem todas as fontes de prova em favor da descoberta da verdade. E de outro, fazê-lo tão rápido, que sua expressão como ônus para o Estado e o réu se tornasse irrisória.

A processualização da justiça representa garantia tão expressiva para os acusados que alguns juristas chegaram a chamar o Código de processo penal - CPP de estatuto protetor dos inocentes. ${ }^{25}$ 
Apesar disso, o proċesso não deixa de ser um sofrimento imposto ao réu, seja ele culpado ou inocente. Quase que se pode repetir, ainda hoje, o que dizia Santo Agostinho a propósito do sofrimento a que estavam sujeitos os processados de seu tempo: para saber se se deve torturar, começa-se por torturar.

Numa época em que os estudiosos procuram criar formas cada vez mais sumárias de procedimento, que possibilitem a justa solução dos casos com menor sacrifício para as partes, a proposta que apresentamos chega a ultrapassar esse objetivo, pois, mais que um processo 'mais rápido', consagra um verdadeiro 'não-processo'.

Sua adoção não implica na impunidade dos criminosos não perigosos, como se alegou, ${ }^{26}$ quando da apresentação do tema pela primeira vez, pois o beneficiado fica sujeito a medidas restritivas de direitos, como as mencionadas, que são - após sua adoção, com excelentes resultados, em outros países - , uma das mais sedutoras realidades do moderno direito penal.

A preocupação maior dos aplicadores da lei está voltada para a verdadeira impunidade dos criminosos de alta periculosidade, que - esta, sim - já existe entre nós, porque, por excesso de trabalho, não processamos com a rapidez necessária e, por falta de lugares nos presídios, não prendemos os autores de crimes mais graves.

As varas criminais das grandes cidades andam afogadas em processos, entre os quais cresce, de maneira assustadora, o número de feitos por crimes violentos. Ai estão as quadrilhas de assaltantes, os traficantes de drogas, um sem número de criminosos violentos, da mais alta periculosidade, a exigir dos juizes mais atenção, maior severidade de tratamento, mais tempo do que têm.

Assim, diminuir o número de processos por fatos de pequena ou de nenhuma gravidade, fazendoo sem prejuizo para a justiça das decisões, significa ganhar mais tempo para a solução dos casos infinitamente mais graves.

\section{Contraditório e justiça das decisões}

O ideal da justiça seria proferir decisões, não apenas justas, como assim tidas pelo interessados. Para isso, o processo é cercado de garantias - uma das quais é a da instrução contraditória - e dá a quem sucumbe o direito de ver sua pretensão reapreciada por outro órgão jurisdicional, de grau mais elevado.

Apesar disso, a verdade real continua sendo um ideal nem sempre atingivel, satisfazendo-se a justiça com a afirmação de uma verdade meramente formal. A só adoção do contraditório é insuficiente para criar a igualdade entre as partes. Uma coisa a lição é de Carnelutti - é que a cada parte corresponda o mesmo direito que à outra; e outra coisa é que cada uma delas tenha a mesma possibilidade de exercitá-lo. O que importa é o efetivo exercício do direito, não sua atribuição. ${ }^{27}$

No resultado de um processo influem não apenas fatores ligados à vontade das partes, mas em todos os casos e de forma decisiva fatores totalmente estranhos a ela. Não é só o fato de não serem as pessoas igualmente ricas, inteligentes, diligentes ou escrupulosas, ou de não poderem ter representantes dotados do mesmo nível de conhecimentos, de habilidade, de correção, ou de esperteza. Além disso, influi na solução do processo a sorte da parte em ter ou em não ter como próvar seu direito.

Pode ocorrer que as testemunhas tenham presenciado o acusado agredir a vítima a socos e ferila, mas não tenham percebido que, antes disso, a vítima tentou matá-lo com uma faca. Neste caso, o acusado teve oportunidade de provar seu direito, apenas não pode fazê-lo.

Tudo isso pode acontecer e de fato acontece em um processo ideal, onde as partes estejam interessadas, apenas, na busca da verdade. Imagine-se o que acontece nos processos reais, onde o que se vê é o interesse em esconder fatos que realmente existiram, em fazer surgir circunstâncias que não aconteceram, tudo isso com a intenção de modificar a verdade.

No juizo criminal, as decisões condenatórias são relativamente justas na quase totalidade, mas, em razão do in dubio pro veo, o mesmo não se pode dizer das sentenças absolutórias - que muitas vezes deixam de condenar o verdadeiro culpado por falta de prova. Em muitos casos, verifica o juiz que é impossível que o réu seja culpado; mais que isso, que é provável que o seja, mas, como isso não é certo, não pode condená-lo. Acontece que a decisão que absolve o culpado, embora menos alarmante, é tão injusta quanto a que condena o inocente.

O que se verifica, portanto, é que a adoção do contraditório, embora suas inegáveis vantagens, não consegue realizar o milagre de suprir essas deficiências próprias do homem. Por isso, pode-se dizer que as decisões da justiça nem sempre fazem justiça às partes.

Há, além disso, um outro aspecto, quase tão importante quanto este: mesmo quando a decisão é justa, nem sempre aquele que perde conforma-se com ela. Este é um dado de psicologia humana a que o legislador não pode deixar de dar importância. À semelhança da mulher de César, a justiça preci- 
sa ser e parecer justa. Ora, não é fácil ser justo, menos, ainda, parecer justo.

\section{A suspensão condicional do pro- cedimento como solução ideal}

A decisão que concede a suspensão condicional do procedimento permite ao juiz não apenas fazer justiça, como parecer justo aos olhos do interessado. A confissão implícita do beneficiado, somada às provas do inquérito policial, será suficiente para dar ao juiz, na quase totalidade dos casos, a certeza de que foi justo, e a livre aceitação da medida por aquele a certeza de que pareceu justo - solução que não se alcança com o sursis.

O beneficiado com o sursis pode dizer se aceita ficar em liberdade em troca de algumas obrigações, ou se prefere ir para a cadeia, mas não tem o direito de dizer que não concorda com a condenação, pois esta já lhe foi imposta, não pode ser modificada, ainda que the pareça injusta.

No sursis e na probation as opções não são entre admitir a culpa e aceitar a pena (ou a restrição) imposta, ou não admiti-la e ser processado. Nos dois casos já houve processo e o réu foi condenado lou declarado culpado), de modo que só Ihe resta escoIher entre ir para a prisão ou ficar em liberdade sob condições

Na suspensão condicional do procedimento a aceitação ou recusa do benefício é livre. Ou o favorecido admite que é culpado e aceita a medida, ou não admite e poderá demonstrar sua inocência no processo que se seguir. Nos EUA, como se sabe, em alguns casos o indiciado escolhe entre confessar a culpa e ser condenado desde logo, ou negá-la e exigir um julgamento normal. Esta escolha, no entanto, não é livre, pois se afirmar que não é culpado, assume o risco de, se vier a ser condenado no processo, sofrer uma pena muito maior do que aquela.

Nesse caso, pode acontecer que, mesmo não se considerando culpado, ou pelo menos tão culpado o indiciado aceite a pena menor, que não acha justa, tão-só por acreditar que é difícil a prova de sua inocência.

Na suspensão condicional do procedimento ao contrário, pode-se dizer que a solução, além de justa, será aceita livremente pelo interessado, que não estará sujeito a qualquer prejuízo pelo fato de rejeitála. Se o fizer e vier a ser condenado no processo que se seguir, sua pena não será maior só por isso e o que não é menos importante - ainda poderá obter a mesma vantagem, ou seja, ter sua execução suspensa condicionalmente.

Portanto, o que se verifica é que, além de to- das aquelas vantagens materiais e processuais, que, só por si justificariam a adoção do instituto, tem ela outra ainda maior, ainda muito mais importante, pois permite ao juiz não apenas fazer justiça, como também parecer justo aos olhos de todos. A confissão continua sendo a rainha das provas. Ora, a confissão implícita do beneficiado, somada às provas do inquérito, basta para dar ao juiz a certeza de que foi justo; a livre aceitação da medida por aquele, a de que pareceu justo.

Esta é uma qualidade inestimável, que, apesar do contraditório, nenhuma outra decisão logra obter, qualidade que os juristas consideram praticamente inalcançável, mas que é possível atingir com a modificação ora proposta.

\section{Notas}

1. O Tratamento em liberdade no direito francês. Trad. de Alipio Silveira. Justitia. p.74-91.

2. DOTTI, René Ariel. Conferência na ESMAN. Rio de Janeiro, UERJ, 1981

3. BARAUNA, José Roberto. Liç̃es de processo penal. 2.ed. São Paulo, Buschatsky, 1979, p.148. p. 55 .

4. ARRAYA, José. Escarcelación provisoria. Rosario, 1938,

5. A crise de confiança no sistema penal e, em particular, nas prisões. Trad. Alice Klauss, Revista de Direito Penal. v. 21/2, p. 43

6. Il Semana Internacional de Criminologia. Notas de Romão Portão. São Paulo, s.d

7. RICO, José M. Sanções penais. Trad. de Sérgio Fragoso. Rio de Janeiro, 1978 , p. 100

8. RICO, José M. op. cit. p. 91-92.

9. Novo direito penal. 1971. v.3, p. 109-11.

10. O discurso de alguns membros do grupo, lógico, inteligente, mostra quão perigosos são.

11. Relatório do DCN. 9. 6.77, p. 1.338.

12. RICO, José M. op.cit. p. 133-134.

13. PISAPIA, Gian Maria. Reflessioni in tema de recidiva Riv. Italiana de Diritto e Procedura Penali. 4 (4): $967 / 75$.

14. BETTIOL, Giuseppe. II mito della rieducazione. Riv. de Diritto e Procedura penali. 6 (3): 705/712.

15. VASSALI, Giuliano. Funzioni e unsufficienze della pena. Riv. di Diritto e Procedura Penali. 4 (2): 339

16. Anteprojeto de Código penal. arts. 46/48.

17. UERJ, com presença juizes e professores.

18. I Simpósio Sul-Brasileiro sobre Problemas Atuais da Justiça Criminal. Ajuris, 1980. p. 139.

19. Código penal. Salvo a hipótese do art. 46 , $\S$ único.

20. Documento de trabalho. VI Congresso da ONU. Caracas, 1980

21. DOTTI, René Ariel. Bases e alternativas para o sistema penal. Saraiva, 1980. REALE JÚNIOR, Miguel. Humanizar e punir. Boletim do CNPP. 1 (1): set. 1981. 
22. Proposta apresentada no Seminário sobre a Reforma dos Códigos Penal e de Processo Penal, na ESMAN, na UERJ, set. 1981.

23. FLORIAN, Eugene. Elementos de derecho procesal penal. Trad. de P. Castro, s.d. p. 250.

24. Relação ao Projeto Preliminar de Códigos de Processo penal italiano, de 1955.
25. TORNAGHI, H. Instituições. v.1, p.10.

26. Alegação de ilustre professor, durante os debates, na apresentação do tema.

27. Derecho y proceso. Trad. de s. Senus Melendo. s.I., Ejea. p. 294. 